NBER WORKING PAPER SERIES

ARBITRATOR DECISION MAKING:

WHEN ARE FINAL OFFERS IMPORTANT?

Max H. Bazerman

Henry S. Farber

Working Paper No. 1183

NATIONAL BUREAU OF ECONOMIC RESEARCH

1050 Massachusetts Avenue

Cambridge, MA 02138

August 1983

This research was supported by the National Science Foundation under grants No. SES-8207703 and No. BNS-8107331. Farber was also supported by the Sloan Foundation as an Alfred P. Sloan Research Fellow. The authors would like to thank Harry Katz and participants in a workshop at Princeton University for helpful comments. The research reported here is part of the NBER's research program in Labor Studies. Any opinions expressed are those of the authors and not those of the National Bureau of Economic Research. 
NBER Working Paper $\$ 1183$

August 1983

Arbitrator Decision on Making: When are Final Offers Important?

ABSTRACT

Central to understanding the effect of arbitration schemes on the process of collective bargaining is understanding the process by which arbitrators make decisions. A model of arbitrator behavior in conventional arbitration is developed that allows the arbitration award to be a function of both the offers of the parties and the (exogenous) facts of the case. The weight that the arbitrator puts on the facts relative to the offers is hypothesized to be a function of the quality of the offers as measured by the difference between the offers. Two special cases of this model are derived: 1) the arbitrator bases the award strictly on the offers of the parties (split-the-difference) and 2) the arbitrator bases the award strictly on the facts of the case.

The model is implemented empirically using data gathered from practicing arbitrators regarding their decisions in twenty-five hypothetical cases. These data have the advantage that they allow causal inference regarding the effect on the arbitration award of the facts relative to the offers. On the basis of the estimates, both of the special case models are strongly rejected. The arbitration awards are found to be influenced by both the offers of the parties and the facts of the case. In addition, the weight put on the facts of the case relative to the offers is found to vary significantly with the quality of the offers. When the offers are of low quality (far apart) the arbitrator weights the facts more heavily and the offers less heavily.

These results suggest that the naive split-the difference view of arbitrator behavior, which is the basis of the critique of conventional arbitration that has led to the adoption of final-offer arbitration, is not correct in its extreme view. On the other hand, the awards are affected by the offers so that the parties can manipulate the outcome to some extent by manipulating their offers. However, the scope for this sort of influence is limited by the finding that the offers are weighted less heavily as their quality deteriorates.

Max H. Bazerman

Sloan School of Management

MIT

E52 - 5th floor

50 Memorial Drive

Cambridge, MA 02139
Henry S. Farber

Center of Advance Study in

Behavioral Science

202 Junipero Serra Blvd.

Standford, CA 94305 
I. Introduction

Of central importance in the process of collective bargaining is the mechanism for settling disputes that arise when the parties fail to reach agreement. It determines not only the terms of agreement in all cases but also the probability of reaching agreement without resort to the dispute settlement mechanism. While the strike is the dominant mode for settling disputes that arise in the course of negotiating labor contracts, arbitration procedures have become particularly important in areas, such as the public sector, where strikes are not allowed. These procedures are characterized by a third party making a binding decision.

The willingness of the parties to make concessions in order to reach a negotiated settlement is based largely on what they expect to receive if they do not reach agreement. In the case of arbitration, the parties' expectations regarding the outcome in the event of failure to reach a negotiated settlement depend heavily on their expectations regarding the behavior of the arbitrator. Thus, our ability to understand the effects of an arbitration scheme on the collective bargaining process without understanding the decision processes of the arbitrators themselves is quite limited. However, there has been little in the way of systematic analysis of how arbitrators actually decide. ${ }^{1}$

In this study the decision process of arbitrators in a conventional arbitration scheme, where arbitrators are free to impose any settlement they see $f i t$, is analyzed. While the use of this type of arbitration has been increasing, critics have identified a number of potentially troublesome implications for the bargaining process. ${ }^{2}$ 
The most important of these is the possibility that the arbitrator will "split the difference" between the offers of the parties resulting in a "chilling" of bargaining and excessive reliance on the arbitrator to reach agreement. ${ }^{3}$ This may occur as the parties maintain polar positions in order to influence the arbitration award most favorably.

In order to evaluate this argument as well as to investigate the arbitration process more generally, a model of arbitrator behavior is built that nests two extreme views of the process. The first is the view that arbitrators simply split the difference between the offers of the parties untainted by the facts of the case. The second is the naive view that arbitrators examine the facts of a case and impose a settlement that is deemed fair untainted by the offers of the parties. 5 The empirical implementation of this model will shed light on the extent to which the arbitrator splits-the-difference as opposed to fashioning an award based on the facts of the case.

In order to implement this model empirically it is necessary to collect data on the decisions of arbitrators. However, data on arbitrators' decisions in actual cases of the sort generally analyzed have serious limitations. Consider the case where the investigator is forced to rely on decisions in actual cases in making inferences regarding the degree to which the arbitrator is influenced by the offers of the parties in formulating an award. It is certainly true that the offers of the parties are affected by all of the facts of the particular case and that the investigator is not able to observe all of the facts. Thus, simply finding that the arbitrator's decision is related to the offers of the parties after controlling for the 
observed facts is not sufficient to conclude that the arbitrator is, in fact, influenced by the offers of the parties. It may be that any relationship between the arbitration award and the offers of the parties is a statistical artifact of omitted unobserved facts of the case, themselves correlated with the offers of the parties, that are observed by the arbitrator and utilized directly in fashioning an award. Thus, it is impossible to infer causality regarding the direct effect of the offers on the behavior of the arbitrator from data on the decisions of arbitrators in actual cases.

In light of these problems, the nested model is implemented empirically using data gathered from practicing arbitrators who were each asked to decide the same set of twenty-five hypothetical cases. In the simulation exercise used here, the arbitrators were given a precisely controlled set of information regarding the facts of each case along with information regarding the offers of the parties. All of the variation in the facts is measured in the data. Thus, the information set of the arbitrator is completely characterized by the observed facts of the case, and the offers of the parties cannot be proxying for factors that the arbitrator observes but are not observed by the investigator. Any effect of the offers of the parties. on the arbitration award that is found using data from the simulation exercise after controlling for the facts of the case can properly be interpreted causally as the "pure" effect of the offers.

In the next section the model of the arbitrator's decision process is developed in detail. The model allows both the facts of the particular case and the offers of the parties to have an effect on the outcome. The model is generalized so that the weight that the 
arbitrator puts on the facts of the case relative to the weight put on the offers of the parties is a systematic function of the "quality" (reasonableness) of the offers. More specifically, the weight that the arbitrator puts on the facts of the case is argued to be a direct function of the difference between the offers. Thus, when the parties are near agreement (offers close together), the arbitrator has little discretion in making an award. The aribtrator simply ratifies what the parties have nearly agreed upon. On the other hand, when the parties are far from agreement (offers far apart), the arbitrator has a considerable degree of latitude in making an award, and the facts of the case have an important influence.

Four special cases of the general model are derived. The first is where the arbitrator considers only the facts of the case. The second is where the arbitrator simply splits the difference between the offers of the parties. The third is a slight generalization of the second where the arbitrator compromises between the offers of the parties but where the offers are weighted unequally in forming a compromise. The Einal special case is where the arbitrator considers a fixed weight combination of the facts of the case and the offers of the parties in formulating an award.

In section II the design of the simulation exercise is discussed and the resulting sample is described. Section IV contains the empirical specification of the models of arbitrator choice. In section $V$ the models are estimated using the data from the simulated arbitrations. It is found that all four of the special cases can be rejected easily in favor of the model where the arbitrator considers both the facts of the case and the offers of the parties and where the 
relative weights put on these factors are strongly influenced by the quality of the parties' offers. The final section contains a summary and analysis of the results.

\section{A Model of Arbitrator Behavior}

Consider an arbitrator who must make a decision regarding a single issue such as the wage change to prevail in a collective bargaining agreement. ${ }^{6}$ An idealized model of the determination by arbitrators of an award in a particular case is that they examine the facts of the case, use these to determine an appropriate settlement, and impose this judgement as the award.7 In more formal terms,

$$
Y_{s}=Y_{e}
$$

where $Y_{s}$ represents the arbitration award and $Y_{e}$ represents the arbitrator's notion of an appropriate settlement based on the facts of the case.

Another idealized model of the determination by arbitrators of an award in a particular case is that they split the difference between the offers of the parties. In more formal terms this is

$$
Y_{s}=\left(Y_{m}+Y_{u}\right) / 2
$$

where $Y_{m}$ represesents the offer of the management and $Y_{u}$ represents the offer of the union. A more general version of this model is that the arbitrator is "biased" in the sense that the offers of the parties are not weighted equally, although the award is still based on the final offers exclusively. This can be expressed as

$$
Y_{s}=d Y_{m}+(1-d) Y_{u}
$$

where $d$ is a parameter between zero and one that represents the relative weight put on the managements' offer. ${ }^{8}$

These idealized models all are inadequate. Consider first the 
model embodied in equation 1. To argue that arbitrators ignore the offers of the parties and impose what they feel is appropriate based strictly on the facts of the case disregards a large literature which suggests that arbitrators place a great deal of emphasis on the offers of the parties. 9 There are a number of reasons why arbitrators would consider the offers of the parties. First, they may be concerned that the settlement imposed on the parties is acceptable to both parties so that it is workable and contributes to the long run stability of the collective bargaining relationship. One way to ensure the workability of an award is to consider the explicit demands of the parties. ${ }^{0} \mathrm{~A}$ second reason why the arbitrator might consider the offers of the parties is that they may contain information about the facts of the case that cannot be conveyed directly to the arbitrator in any other fashion. However, the potential usefulness of the offers of the parties to transmit information to the arbitrator will be undermined by the desire of the parties to manipulate the award through manipulation of their offers. In other words, the arbitrator will not be able to determine whether a position taken by one of the parties represents real information or strategic behavior by the party in question. A final reason why the arbitrators might consider the offers of the parties is that they have an obvious desire to be called upon in the future, and one way to do this would be to consider the explicit demands of the parties. ${ }^{11}$

It is also foolish to argue, as the models in equations 2 and 3 suggest, that arbitrators ignore the facts of a case and focus exclusively on the offers of the parties. If this were true then the parties would have the incentive to make their final offers very 
extreme. An important factor in keeping the offers reasonable must be that the aribtrator would judge extreme offers to be unreasonable and put less weight on such offers. 12 As a matter of logic it must be true that in order to judge an offer to be reasonable or unreasonable the arbitrator must have a standard against which to judge offers. This standard is sure to be based on the facts of the case.

What is clearly required is a model which allows the arbitration award to be a function of both the facts of the case and the offers of the parties. A very simple model of this type is

$$
Y_{s}=g Y_{e}+(1-g)\left(d Y_{m}+(1-d) Y_{u}\right)
$$

where the parameter $g$ represents the weight that the arbitrators put on their notion of what is appropriate (the facts) in formulating an award. The quantity $(1-g) d$ is the weight that the arbitrators put on the management's offer while $(1-g)(1-d)$ is the weight that arbitrators put on the union's position.

The earlier models are all special cases of this model. The model embodied in equation 1 (only the facts matter) is the special case where $g=1$, the model embodied in equation 2 (the pure split-thedifference model) is the special case where $g=0$ and $d=1 / 2$, and the model embodied in equation 3 (general split the difference model) is the special case where $g=0$. The general model will be estimated in section $V$ along with the special cases both in order to test the validity of the special cases and in order to estimate the weights placed on the facts of the case and the offers of the parties.

There is still a serious problem with even the general specification contained in equation 4. This is that the weight $(g)$ that arbitrators puts on their own interpretation of the facts is 
assumed to be unaffected by either the facts or the offers of the parties. Once again, the parties will have the incentive to make their offers as extreme as possible. This is clear from equation 4 , where an increase (decrease) in the offer of either party increases (decreases) the arbitration award. A more realistic model would allow for the weights to vary with the quality of the offers of the parties. One mechanism by which these weights could vary is that arbitrators ought to have more flexibility in fashioning an award when the offers of the parties are far apart than when they are close together. The crux of this argument is that arbitrators are attempting to fashion an acceptable and fair award. In order to do this they may feel free to interpret the facts of the case in their own way when the parties are far from agreement, but when the parties are close to agreeing on the basis of their offers they will not want to stray far from the nearly agreed upon settlement. ${ }^{13}$

Another interpretation of this mechanism for variation of the weights is that as the the offers of the parties become more extreme (less reasonable) the arbitrator ought to weight them less in fashioning an award. This embodies the solution to the problem of why the positions of the parties do not diverge to extreme values: As the offers diverge, the arbitrator recognizes that they are unreasonable in light of the facts and at least partly disregards them.

In the context of the model contained in equation 4 , variable weights can be introduced in a rather straightforward fashion. Let

$$
g=E\left(Y_{u}-Y_{m}\right)
$$

where $f$ is a monotonically increasing function of the difference between the offers of the parties. In other words, the weight that 
the arbitrator puts on the facts of the case relative to the offers of the parties is a direct function of how far apart the parties offers are. It also seems reasonable to expect that the function $f$ has two other properties. First, it ought to be true that $f(0)=0$ so that if the parties are in virtual agreement then the arbitrators essentially ratify that agreement by putting no weight on their interpretation of the facts. Second, it ought to be true that as the difference between the offers of the parties grows very large the arbitrators essentially disregard these offers and put full weight on their interpretation of the facts $(g=1)$.

It is interesting to note that this specification allows the overall weight put on the offers ( $g$ ) to vary without allowing the relative weight put on the two offers (d) to vary. First, as the offers of the parties diverge the arbitrator puts more weight on the facts. This follows directly from the specification of the $f$ function. Second, as the offer of either party becomes extreme so that it may be deemed unreasonable, the difference between the offers will increase resulting in a decrease in the weight put on the offers and an increase in reliance on the facts of the case. Thus, it is no longer necessarily true that an increase (decrease) in either offer will increase (decrease) the arbitration award. As will be demonstrated later, the reduction in the weight put on the offers may outweigh the increase (decrease) in the offers themselves.

It must be pointed out that there are many potential specifications for a model embodying the mechanisms outlined above. However, they all yield a similar set of empirical implications, and the model specified here is rich enough to capture a wide range of 
potential variation in the data. Before turning to the empirical implementation of the model, the sample of arbitrators and the simulations used to generate the data are described in the next section.

\section{The Data}

The data used in this study were collected from a set of simulations administered to practicing arbitrators. The simulation materials were sent out to the entire membership of the National Academy of Arbitrators and the participants in a regional meeting of the American Arbitration Association. Each arbitrator was asked to judge twenty-five hypothetical interest arbitration cases where the only remaining unresolved issue was wages. They were asked to provide the wage award for a contract of one year duration that they would make under a conventional arbitration scheme. Along with their judgements in the twenty-five cases each arbitrator was asked to supply information regarding his or her background and experience. Arbitrators were required to supply their names and addresses with their response only if they wished to receive a copy of the results. Anonymity was guaranteed, and responses were sent back in a provided business reply envelope.

OE 584 sets of materials mailed, fifty-nine arbitrators provided usable responses for all twenty-five cases. The mean age of the response group was 58.2 years, and all but two of the respondents were male. ${ }^{4}$ The mean number of interest arbitration cases that had been heard by members of the response group was 128 , while the the mean number of arbitration cases of all sorts that had been heard was 988 . 
While there is no way of knowing whether the response group is representative of the population of arbitrators as a whole, it is likely that those who responded were those who felt most comfortable making an award on the basis of the information provided and who believe that the salient features of a real collective bargaining situation can be captured in a simulation. It is difficult to speculate about the effect that this might have on the results.

Each of the twenty-five hypthetical cases was described in a paragraph in terms of seven criterion factors. For each factor there were five possible levels. In the total set of twenty-five cases there were five cases for each of the five levels of each factor.

In order to maintain parallelism between cases while providing necessary diversity, twenty-five industries were identified that had varying average national wages in 1980 . These national wages were adjusted very slightly to create a systematic pattern of twenty-five national wages that varied from $.40, .45, .50, \ldots .1 .55,1.60$ times $\$ 8.66$, where $\$ 8.66$ was the mean of all twenty-five actual national industry average wages. These adjusted national wages were used as a basis for the computation of some of the factors as described below. Along with information on the national wage, each scenario contained information on seven factors.:

- The inflation rate was stated to be $7 \%, 9 \%, 11 \%, 13 \%$, or $15 \%$.

- The average arbitrated wage increase of other contracts in the industry was stated to be $6 \%, 8 \%, 10 \%, 12 \%$, or $14 \%$.

- The average local wage for similarly qualified employees was stated to be equal to the average national wage in the industry times $87 \%, 94 \%, 101 \%, 108 \%$, or $115 \%$. 
- The present wage was stated to be equal to the average national wage times $96.5 \%, 98 \%, 99.5 \%, 101 \%$, or $102.5 \%$.

- The financial health of the firm was stated to be terrible, poor, fair, good, or excellent.

- Management's final offer was stated to be equal to the average national wage in the industry times $104 \%, 105.5 \%, 107 \%, 108.5 \%$, or $110 \%$.

- Union's final offer was stated to be equal to the average national wage in the industry times $111.5 \%, 113 \%, 114.5 \%, 116 \%$, or $117.5 \%$.

Two additional criteria were used in selecting the particular values for each factor. First, it was desired that the scenarios develop wage increases rather than wage declines. Second, it was necessary that for all scenarios the union's final offer exceed that of the management for obvious reasons.

The scenarios were developed by pairing each of the five levels of each factor once, and only once, with all five levels of each other factor. ${ }^{15}$ Thus, the number of possible combinations of any two factors is equal to five times five or twenty-five, which is equal to the number of cases in the simulation. The following is an example of a simulated case:

\section{Situation 18}

In a town of 102,000 people, workers with similar skills and backgrounds to the employees of this radio and broadcasting company were paid $\$ 8.31 / \mathrm{hr}$., while the national wage in this industry was $\$ 8.23 / \mathrm{hr}$. The financial outlook for this company is fair in light of the $11 \%$ inflation rate. The present average wage for this company's union is $\$ 8.44 / \mathrm{hr}$. Contract negotiations have reached an impasse. Both sides, however, have agreed to submit final offers to you, the arbitrator, and to be bound by your decision for a period of one year. Comparable pay increases from 
collective bargaining agreements in the industry are running about $8 \%$ this year. Management's final offer is $\$ 8.56$ (a $1.4 \%$ increase) and the union's final offer is $\$ 9.55$ (a $13.2 \%$ increase).

As Table 1 shows, there is considerable variation in the responses of the arbitrators within particular cases. The standard deviation of the percent wage increase awarded by the arbitrator in a particular case is never below 1.1 percent and is generally much larger. Thus, arbitrators differ substantially in their evaluation of any particular scenario, and these differences may be a major source of the uncertainty that has been argued to drive collective bargaining where arbitration is the dispute settlement mechanism. ${ }^{16}$

The analysis contained in the next section will be based on the proportional wage increase awarded by the arbitrators. This can be approximated by the difference between the logarithm of the wage level awarded and the logarithm of the present wage. ${ }^{17}$ This will be called here the log difference of the arbitrated wage from the present wage. On this basis the relevant form for the explanatory variables that measure wages are as log differences from the present wage. The only variables that do not measure wages or proportional changes are the variables measuring the financial condition of the company. Two dichotomous variables were created to measure variation in this dimension. The first (CONDB) equals one if the financial condition of the firm was terrible or poor, and it equals zero otherwise. The second (CONDG) equals one if the financial condition of the firm was good or excellent, and it equals zero otherwise. The omitted catagory is a firm financial condition of fair. The definitions, means, and standard deviations of the variables used in the empirical analysis are contained in Table 2 . 


\section{The Empirical Specification}

In order to implement the models of arbitrator choice outlined in section II, a specification of the arbitrator's notion of an appropriate settlement $\left(Y_{e}\right)$ is required. This must be based only on the facts of the case and not on the offers of the parties. A convenient specification for $Y_{e}$ is

$$
\mathrm{Y}_{\mathrm{e}}=\mathrm{XB}
$$

where $X$ represents a vector of variables reflecting the facts and $B$ represents a vector of parameters. The vector $\mathrm{x}$ includes a constant and variables measuring (1) the rate of inflation; (2) arbitration awards in comparable situations; (3) the differential between the local wage for comparable work and the present wage; (4) the differential between the national wage in the industry and the present wage; (5) the logarithm of the present wage; and (6) the financial condition of the company. The definitions of these variables are contained in Table 2.

Assuming an additive error, equation 1, representing the model of the arbitrator decision process where the arbitrator's notion of an appropriate award is simply imposed, can be rewritten as

$$
\mathrm{Y}_{\mathrm{s}}=\mathrm{XB}+\mathrm{e}
$$

where e represents unmeasured components affecting the arbitration award. Under the same stochastic assumption, equations 2 and 3 , representing the constrained and unconstrained versions respectively, of the split-the-difference model of the arbitrator decision process are simply augmented by the additive error (e). The more general model contained in equation 4 and embodying both of the simple models 
can be written with an additive error as

$$
\mathrm{Y}_{\mathrm{s}}=g X B+(1-\mathrm{g})\left(d \mathrm{Y}_{\mathrm{m}}+(1-d) \mathrm{Y}_{u}\right)+e .
$$

Each of the empirical models defined in this paragraph can be estimated using ordinary least squares (OLS). The general model in equation ( 8 ) is estimated by regressing $Y_{S}$ on $X$ and the offers of the parties. It is clear from equation 8 that the sum of the coefficients on the offers from the OLS regression is equal to $1-g$ and that the ratio of the coefficient on the management offer from the oLs regression to $1-g$ is equal to $d$. Thus, both the weight that the arbitrator puts on the interpretation of the facts of the case (g) and the weight placed on the management offer relative to the union offer (d) can be recovered in a straightforward fashion from the ous estimates.

The final model to be estimated allows the weight on the facts of the case to vary with the quality of the offers. Thus, an empirical specification is required for the weighting function $\left(g=f\left(Y_{u}-Y_{m}\right)\right.$ ) defined in equation 5. A convenient parameterization for this function that has the required properties is

$$
g=1-\operatorname{ExP}\left[g_{0}+g_{1}\left(Y_{u}-Y_{m}\right)\right]
$$

where $g_{0}$ and $g_{1}$ represent the parameters of the function. This parameterization is rich in allowing for testable empirical hypotheses. Most importantly, the notion that the weight the arbitrator puts on the notion of an appropriate award (the facts of the case) is a direct function of how far apart the parties' offers are is embodied in this specification as $g_{1}<0$. If $g_{1}$ is not significantly less than zero then the notion that the weights are dependent on the quality of the offers cannot be rejected in the 
context of the empirical specification used here. In addition, the hypothesis that the arbitrator have no discretion $(g=0)$ in the case where the the parties' offers are congruent $\left(Y_{u}=\cdot Y_{m}\right)$ is embodied in the specification as the hypothesis that $g_{0}=0$. After substituting equation 9 into equation 8 for $g$, the model can be estimated straightforwardly by nonlinear least squares (NLLS), and each of these hypotheses can be tested directly.

Before presenting the estimates, it is interesting to note that the sample design seems to be a natural for application of an error components model of some sort. There are twenty-five observations for each of the arbitrators, and it is likely that the arbitrators differ systematically in their awards across the twenty-five cases. If this difference can be captured by differences in the intercept in the appropriate award function (equation 6) then a fixed effect model which allows for arbitrator specific dummy variables would be appropriate. ${ }^{18}$ However, each arbitrator was given the same set of twenty-five cases so that the explanatory variables $\left(X, \bar{Y}_{m}, \bar{Y}_{u}\right)$ are the same for all arbitrators in each case. In this situation it can be shown for the oLS models that the estimates derived without the fixed effects are identical to those obtained when the fixed effects are included. 19 In addition, it can be shown that the standard errors derived from the model including the fixed effects must be smaller than those derived from the model without the fixed effects. Thus, any hypothesis testing done on the basis of the oLS estimates without the fixed effects will be conservative.

While these results are not precisely true for the NLLS model, all of the results presented below and derived using NLLS were 
reestimated including fixed arbitrator effects. The results were virtually unchanged with respect to both the parameter estimates and the estimated standard errors. With these considerations in mind, the analysis proceeds without an error components structure and with the understanding that the results are identical to those that would be obtained with such a structure. 20

V. The Empirical Results

Table 3 contains estimates of the OLS versions of the model. The first column of the Table contains estimates of the model of arbitrator decision making where the arbitrators simply award what they feel is a fair settlement without considering the offers of the parties. It is clear that the facts play a very important role in determining the award, and with a few exceptions the results accord with what one would expect. In general, higher inflation, higher arbitrated settlements elsewhere, and higher relative earnings for comparable workers (both national and local) all lead to a larger proportional wage increase awarded by the arbitrator.

There are two somewhat unexpected results. First, the log level of the present wage is significantly positively related to the proportional wage increase awarded by the arbitrator, which suggests where wages are already high the proportional increase awarded will be larger. The result will be a wage structure with wage differentials that are increasing over time. This will be examined further with regard to the other models.

The second unexpected result is that the decrease in the award 
due to subpar company financial condition is estimated to be over twice as large as the increase in the award due to a better than average company financial condition. The hypothesis that the "reward" (to the union) when the company is strong is of the same magnitude as the "penalty" when the company is weak can be rejected at any reasonable level of significance. ${ }^{21}$ This result is potentially very important becuase it implies that, in situations where conventional arbitration is the dispute settlement mechanism and where workers settle for smaller wage increases because their employer is in financial difficulty, they will not be able to recover fully their concession when the firm is in good financial condition.

The second column of Table 3 contains estimates of the simple split-the-difference model which contains only a constant and the average of the final offers of the parties. While it is clear that the average final offer is significantly correlated with the arbitration award, it is also true that the constant is significantly different from zero so that the pure split-the-difference model is rejected. The third column of Table 3 contains the slightly more general version of the split-the-difference model where the offers of the two parties can have different effects on the outcome. Once again the constant is significantly different from zero, but the striking result is that the weight that the arbitrator puts on the management final offer is estimated to be over twice as large as the weight that the arbitrator puts on the union final offer. The hypothesis that the weights are equal can be rejected at any reasonable level of significance. 22 of course, this may well be due to the possiblity that the arbitrators found the management final offer more reasonable, 
but this model can take no explicit account of the quality of the offers.

The estimates contained in the fourth column. of Table 3 relate to the model with the variables reflecting both the facts of the case and the offers of the parties included. It is clear that both classes of variables contribute significant explanatory power. The models contained in the earlier columns of the table are nested in this model, and both of the special case models can be rejected. The hypothesis that arbitrators simply impose what they deem fair on the basis of the facts of the case without reference to the offers of the parties can be rejected at any reasonable level of significance. 23 In addition, the hypothesis that the arbitrators base their awards solely on the offers of the parties without reference to the facts of the case can be rejected at any reasonable level of significance. 24 The substantive results are virtually unchanged from the simpler models. The "penalty" for subpar company condition is significantly larger than the "reward" for better than average company condition, and the weight on the management offer is significantly larger than the weight on the union offer. However, even this more general model does not allow the relative weights placed on the offers of the parties to vary with the quality of the offers so that the asymmetry noted for the estimated weights may still be due to systematically more reasonable (from the arbitrator's viewpoint) management offers. One anomalous result from the earlier model at least partly disappears. The level of the present wage is no longer a significant (at conventional levels) determinant of the proportional wage increase awarded by the arbitrator. 
It is straightforward to recover the coefficents of the underlying components of the model $(B, g, d)$ from the estimates contained in the last column of Table 3 using the relationship defined in equation 8 and assuming that $g$ is a fixed parameter to be estimated. This tranformation of the estimates is contained in the first column of Table 4. Isolated here are the determinants (XB) of the arbitrator's notion of an appropriate award, the weight (g) that the arbitrator puts on this notion, and the relative weight (d) that the arbitrator puts on the positions of the parties.

This transformation of the results into the terms of the formal structure contained in equation 8 highlights two results. First, the weight that arbitrators put on their notion of an appropriate settlement is estimated to be significantly greater than one half but significantly less than one. This weight $(g)$ is computed as one minus the sum of the coefficients on the offers of the two parties, and it is estimated to be .641 with a very small (.0355) standard error. The second result, noted above, is that the weight that the arbitrator puts on the management offer is estimated to be three times as large as the weight put on the union offer. This weight (d) is computed as the ratio of the coefficient on the management offer to the sum of the coefficients on the two offers, and it is estimated to be .753 with a small (.055) standard error.

To this point the weight that the arbitrators put on their notion of an appropriate settlement (the facts) as opposed to the offers of the parties has been assumed to be fixed and uninfluenced by the quality of the offers. The model developed in earlier sections and embodied in equations 8 and 9 allow this weight to be a function of 
the quality of the offers. More specifically, the weight put on the notion of an appropriate settlement (the facts) is hypothesized to be a direct function of the difference between the offers of the parties. As the offers of the parties diverge, perhaps through "unreasonableness" on the part of one or both parties, it is hypothesized that the arbitrator pays increased attention to the facts and less attention to the offers.

The estimates of this nonlinear model, derived using NLLS, are contained in the second column of Table 4 . First note that the estimates of the determinants of $Y_{e}$ are very close to those contained in the first column and based on the linear model with fixed weights. One minor (and welcome) change is that the coefficient on the level of the present wage is not a significant determinant of the arbitrator's notion of an appropriate wage increase.

With respect to the weights, the central hypothesis is strongly consistent with the data. The weight that the arbitrator puts on the notion of an appropriate award is estimated to be a direct function of the difference between the offers. This hypothesis is imbedded in the model as $g_{1}<0$, and the hypothesis that $g_{1}=0$ can be rejected against this alternative at any reasonable level of significance. In addition, the hypothesis that if the offers of the parties do not differ then the weight on the offers equals one cannot be rejected. This hypothesis is imbedded in the model as $g_{0}=0$, and this hypothesis cannot be rejected at conventional levels of significance. Another interesting result is that when the weights are allowed to vary, the asymmetric treatment of the offers by the arbitrator disappears. In the case where the weights were fixed the relative 
weight on the management offer (d) was estimated to be .753 with a standard error of .055 . When the quality of the offers is allowed to influence the weight on the appropriate award (the facts), the relative weight on the management offer is estimated to be .471 with a standard error of .150 . The hypothesis that the relative weights on the management and union offers are equal $(d=.5)$ cannot be rejected at any reasonable level of significance. Thus, the evidence is consistent with the notion that the arbitrators place equal emphasis on the two offers but that the overall weight placed on the offers vis a vis the facts is a function of the quality of the offers.

Table 5 contains estimates of the weight on the arbitrator's notion of an appropriate award (the facts) for various values of the difference between the offers of the parties. ${ }^{5}$ Approximations to the standard errors are also included based on a first order approximation to the weighting function derived in equation 9. Note first that the value of the weight when the difference between the offers is zero is not significantly different from zero. This value of the weight rises rapidly with the difference between the offers. At the mean value of the difference in the sample (.0675 or 6.75 percentage points) the weight on the facts is fully 0.651. Thus, at the mean of the sample the weight on the offers is only .349. As the difference between the offers increases above the mean, the weight on the facts rises still further. At two standard deviations above the mean (.122) over 80 percent of the weight is on the appropriate award and less than one fifth is on the offers themselves.

Overall, the results provide strong evidence that arbitrators consider both the exogenous facts of the case, perhaps in the context 
of their notion of an appropriate award, and the offers of the parties in formulating an award. In addition, the relative weight put on the facts versus the offers depends heavily on the quality of the offers. As the offers diverge, it was found that the arbitrators pay increased attention to the facts and less attention to the divergent offers.

\section{Summary and Conclusions}

Two simple (and admittedly extreme) models of the decision process of arbitrators in conventional interest arbitration were developed. The first was that the arbitrators evaluate the facts of a case (as opposed to the offers of the parties) and make an award based on what they deem fair. The second was that arbitrators make an award based strictly on the offers of the parties (splits the difference) without regard to the facts of the case. It was argued that these two models are not likely to be good representations of the arbitrator decision making process on a priori grounds. A more general model in which the award is affected by both the facts of the case through both the arbitrator's notion of an appropriate award and the offers of the parties was then developed. In addition, the more general model allowed the weight that the arbitrator put on the facts relative to the offers to be a function of the quality of the offers.

The various models were implemented using data gathered from practicing arbitrators regarding their decisions in twenty-five hypothetical cases. These cases varied in a number of different factual dimensions regarding the economic environment as well as in the offers submitted by the two parties. On the basis of the estimates, both of the simple models are strongly rejected. The awards are influenced by both the facts of the case and the positions 
of the parties. In addition, when weight put on the facts of the case is allowed to vary with the quality of the offers, it is found that the arbitrator relies significantly more heavily on the facts and less heavily on the offers when the offers are of low quality (far apart).

These results have a number of implications. First, the naive split-the-difference view of arbitrator behavior, which is the basis of the critique of conventional arbitration that has led to the adoption of final-offer arbitration, is not correct in its extreme view. The arbitrators are influenced by the facts independently of the offers. In addition, the finaing that the weight that the arbitrator puts on the offers in making an award is affected by the quality of the offers suggests that there are limits to the degree to which the parties can manipulate the arbitration award by manipulating their offers. For example, if the union's offer is extreme (high) enough then a further increase in the union's offer may actually decrease the arbitration award. Similarly, if the management's offers is extreme (low) enough then a further decrease may actually increase the arbitration award.

In order to illustrate this important result more clearly, consider the following example. Suppose an arbitrator makes decisions in a manner consistent with the nonlinear model defined in equations 8 and 9 , the estimates of which are contained in the second column of Table 4. If the arbitrator's notion of an appropriate award ( $\left.Y_{e}\right)$ based on the facts is 6 percent and the union and management offers are fifteen percent and five percent respectively, then the computed weight on $Y_{e}$ is 0.781 and the weight on the offers is $1-.781=.219$. The arbitration award will be $(.781) 6+(.219)((.471) 5+(.529) 15)=6.9$ 
percent. However, if the union raised its offer to 20 percent, admittedly an extreme figure, the weight on $Y_{e}$ would increase to .894 and the weight on the offers would fall to $1-.894=.106$. Overall, the arbitration award would fall to $(.894) 6+(.106)((.471) 5+(.529) 20)=$ 6.7 percent. Essentially, the increase in the union offer from 15 percent to twenty percent was more than offset by the decrease in the weight that the arbitrator put on the offers (from .219 to .106). Another implication of the analysis is that the arbitrator cannot be considered a judge who is free from influence by the parties. Arbitration awards do seem to be manipulable within limits by the parties through manipulation of their offers. A numerical example based on the estimates is again useful to illustrate this point. Consider now a situation similar to that described in the preceding paragaraph with the exception that the union is offering ten percent. In this case the weight that the arbitrator puts on the facts is .55 and the weight on the offers is .45 . The arbitration award is $(.55) 6+(.45)((.471) 5+(.529) 10)=6.7$ percent. Thus, an increase in the offer of the union from 10 percent to 15 percent would have the benefit of increasing the arbitration award from 6.7 percent to 6.9 percent based on the computations in the preceding paragraph. In this case the decrease in the weight on the offers from .45 to .219 was not enough to offset the higher union offer. ${ }^{26}$

An important caveat is in order regarding the seriousness with which to consider these particular illustrative calculations. They do illustrate the algebra of the model and the constraint that the decision rule of the arbitrator places on the parties, but they cannot capture the full range of considerations relevant to the formulation 
of offers by the parties. It is reasonable to expect the parties to formulate their offers strategically with some understanding of how they affect the arbitration award. However, it is not reasonable to expect one party to hold its offer fixed as the other party makes its offer more or less extreme in order to gain a strategic advantage. Referring to the example in the previous paragraph, as the union raises its offer from 10 to 15 percent, it is better off only if the management holds its offer at 5 percent. If the management drops its offer to 2 percent as the union raises its offer, then the weight on the facts rises to .858 and the weight on the offers falls to .142 . The arbitration award falls to $(.858) 6+(.142)((.471) 2+(.529) 15)=5.1$ percent, and the union is worse off. Clearly, it is important to consider the mechanism through which the parties formulate their offers. While no solution to this problem is offered here, the results derived in this study illustrate the influence that the decision rule of the arbitrator must have on the parties. 27

Why the arbitrators do consider the offers in formulating their awards is a complex question, and its answer lies beyond the scope of this study. Three possibilities are that the arbitrator may consider the offers 1) in order to increase the acceptability of the award to the parties, 2) in order to increase the likelihood or being hired by the parties in future cases, and 3 ) if it is felt that there is information about the facts of the case in the offers that is not available to the arbitrator directly. This last is a particularly difficult rationale to evaluate given that the strategic behavior on the part of the parties that leads to the offers will tend to make such information unreliable if the parties understand that the 
arbitrator is using the offers in formulating the award.

The advantages of using the decisions of arbitrators in carefully controlled simulations as the basis of analysis in a study of this type are clear. The major advantage is that the facts and offers in each case are carefully controlled so that causal inference regarding the relative weights of facts and offers on the arbitration award is possible. This is not generally true of the necessarily incomplete data gathered from actual arbitrations. On the other hand the simulations suffer from the fact that the situations are artificial by definition and that the arbitrator does not have the same range of information available that is available in actual cases. ${ }^{28}$ Thus, it is impossible to be sure that the judgements of arbitrators in simulated cases are consistent with those they would make in actual cases. Nonetheless, the internal consistency of the responses of the arbitrators demonstrated in the analysis contained in this study suggests that there is substantial information in these simulations that can make a substantial contribution to understanding the behavior of arbitrators.

Overall, substantial progress has been made in analyzing the decision processes of arbitrators in conventional arbitration. In addition, the study has demonstrated the value of using data derived from carefully designed simulations in analyzing the behavior of arbitrators. A number of areas for further research are apparent. For example, since the arbitrator decision process is likely to be central to the process of collective bargaining where arbitration is the dispute settlement mechanism, it would be useful to integrate the results of studies such as this into theoretical and empirical 
analysis of bargaining in an environment that includes arbitration. Finally, it is clear that arbitrators differ in their decision processes, and it would be useful to investigate both the degree to which there are such differences and how these differences affect the bargaining process. 


\section{Notes}

1) One exception to this is a recent study by Ashenfelter and Bloom (1984) who use data from New Jersey in order to analyze the outcomes of both conventional and final offer arbitration in the context of one of the special case models developed below. A second exception is Bazerman's (1983) analysis of idiosyncratic models of arbitrator behavior.

2) Wheeler (1978) and Kochan and Baderschneider (1978) present evidence regarding the diffusion of conventional arbitration schemes.

3) Feigenbaum (1975), Feuille (1975), Northrup (1966), Stevens (1966), Starke and Notz (1981), Bonn (1972), and Anderson and Kochan (1977) present arguments that arbitrators split the difference in conventional arbitration resulting in a "chilling" of bargaining. Farber (1981) presents a theoretical model with implications for the pure split-the-difference model.

4) Throughout this study the "facts of the case" refer to all considerations with the exception of the positions of the parties. In general, the facts can be considered to be exogenous to the bargaining process while the offers of the parties clearly cannot be.

5) Farber and Katz (1979) present a model of the bargaining process where the arbitrator is assumed to impose a "fair" settlement without regard to the positions of the parties.

6) Where there is more than one issue to be decided, the details of the analysis become more complicated but its qualitative nature is unchanged for the purposes of this study.

7) See Farber and Katz (1979) for an analysis of the implications of this simple decision rule for the collective bargaining process. 
8) Note that the simple split the diffrence model contained in equation 2 is a special case of the more general model where $d=1 / 2$.

9) See the references in note 3 .

10) Note that a concern for workability of an award also suggests that the facts of a case be considered so that the arbitrator is cognizant of important economic and political factors.

11) This is related to the argument that the arbitrator would like to find a workable settlement. If an unworkable settlement is imposed then one side or the other would not want to hire the arbitrator again.

12) Farber (1981) develops the implications for the collective bargaining process of arbitrators considering the positions of the parties and making judgements as to their reasonableness.

13) Another model of the arbitrator decision process is based on the notion that the arbitrator is constrained to make an award that lies between the offers of the parties so that the result is always some sort of compromise. In this case the award can be interpreted as a weighted average of the offers of the parties where the weight depends on how the arbitrator evaluates each offer in comparison to some notion of an appropriate settlement. The more reasonable offer would receive a higher weight. The implications of this model are very similar to those of the model described in the text. When the offers are close together, the arbitrator has little discretion in fashioning a compromise. However, when the offers are far apart, the arbitrator has much more discretion in making what is felt to be a reasonable award.

14) The mean charcteristics of the respondents are based on the 
fifty-six of the fifty-nine arbitrators who provided their personal characteristics along with their judgements.

15) This particular design was adopted for the purposes of other research using the same data. See Bazerman (1983).

16) Farber and Katz (1979) and Farber (1981) develop models of the collecitve bargaining process where the uncertainty created by arbitration is central to its operation as a dispute settlement mechanism.

17) Virtually identical empirical results would be derived were the exact proportional differences used rather than the log differences.

18) Bazerman (1983) presents an analysis of differences between arbitrators in the formulation of their awards under conventional arbitration.

19) Of course, there is no single constant in a fixed effect model. The analysis of errors components models in this context is formally identical to the well known seemingly-unrelated-regression problem.

20) Note that these considerations are independent of whether, in fact, the constant terms differ significantly across arbitrators. They only suggest that the estimation and statistical inference regarding the basic variables will be unchanged. In fact, for the models presented below, the hypothesis that the constants are the same for all arbitrators can be rejected marginally at conventional levels using an F-test in the oLS models and using a likelihood ratio test under the hypothesis of normally distributed errors in the NLLS model. 21) In formal terms, this hypothesis is that the sum of the 
coefficients on CONDB and CONDG equals zero. The estimated sum of these coefficients is .00807 with a standard error of .00243 .

22) The difference between the coefficient on MFO and the coefficient on UFO is estimated to be .186 with a standard error of 0.0419 .

23) This is the hypothesis that the coeficients on both MFO and UFO are zero. The appropriate test statistic is 64.25 which is distributed as $F(2,1465)$. The critical value of this distribution at the .01 level of significance is 4.61 .

24) This is the hypothesis that the coeeficients on the seven variables in $X$ are zero. The appropriate test statistic is 104.82 which is distributed as $F(7,1465)$. The critical value of this distribution at the .01 level of significance is 2.64 .

25) The values chosen for the differential include the extreme values 0 and .2 along with the mean value plus and minus zero, one, and two standard deviations. The mean plus and minus two standard deviations covers the observed range of the difference in offers almost exactly. The minimum value in the sample is .0135 , and the mean minus two standard deviations is .0133 . The maximum value in the sample is .121 and the mean plus two standard deviations is .122 .

26) The union will always be better off making its offer larger as long as $d Y_{m}+(1-d) Y_{u}<Y_{e}$. Given that the estimate of $d$ is close to .5, this statement is close to the statement that the union will always be better off with a higher offer as long as its offer is closer to $Y_{e}$ than is the management offer. An analogous result holds for the management offer. Of course, these results are true only if the offer of the other party is fixed. 
27) See Farber (1981) for an analysis of strategic behavior by the parties in formulating their offers in the context of a model similar to that implemented in this study.

28) Bazerman (1983) discusses informal responses from arbitrators who examined the simulations with regard to the lack of detailed information on each case relative to what they see in actual cases. 


\section{REFERENCES}

John C. Anderson and Thomas A. Kochan. "Impasse Procedures in the Canadian Federal Service," Industrial and Labor Relations Review 30 (1977):282-301.

Ashenfelter, Orley and David E. Bloom. "Models of Arbitrator Behavior: Theory and Evidence," American Economic Review (1984)

forthcoming.

Max H. Bazerman. "Arbitrator Decision Processes in Interest Arbitration: A Policy Capturing Approach." (1983) mimeo.

R. L. Bonn. "Arbitration: An Alternative System for Handling Contract Related Disputes," Administrative Science Quarterly 17 (1972): 254-264.

Henry S. Farber. "Splitting-the-Difference in Interest Arbitration," Industrial and Labor Relations Review 35, No. 3 (October 1981): 70-77.

Henry S. Farber and Harry C. Katz. "Interest Arbitration, Outcomes, and the Incentive to Bargain," Industrial and Labor Relations Review 33, No. 1 (October 1979):55-63.

Charles Feigenbaum. "Final Offer Arbitration: Better Theory Than Practice," Industrial Relations 14, No. 3 (October 1975): 311317.

Peter Feuille. "Final offer Arbitration and the Chilling Effect," Industrial Relations 14, No. 3 (October 1975): $302-310$.

Thomas A. Kochan and Jean Baderschneider. "Determinants of Reliance on Impasse Procedures: Police and Firefighters in New York State," Industrial and Labor Relations Review 31 (1978):431-440.

Herbert R. Northrup. Compulsory Arbitration and Government Intervention in Labor Disputes. Washington, D.C. Labor Policy Association, 1966.

Frederick. A. Starke and William W. Notz. "Pre- and Post-Intervention Effects of Conventional vs. Final Offer Arbitration, "Academy of Management Journal 24 (1981):832-850.

Carl M. Stevens. "Is Compulsory Arbitration Compatible with Bargaining?" Industrial Relations 5(1966):38-50.

Hoyt N. Wheeler. "How Compulsory Arbitration Affects Compromise Activity," Industrial Relations 17 (1978):80-84. 
Table 1:

Means and standard deviations of the percent wage increase awarded by the fifty-nine arbitrators in each of the scenarios.

Scenario

1

2

3

4

5

6

7

8

9

10

11

12

13
Mean

(s.d.)

9.53

(1.91)

7.18

(1.53)

7.10

(1.53)

12.06

(1.28)

11.19

(2.14)

10.34

(1.10)

8.66

(1.88)

12.84

$(2.70)$

10.14

(1.89)

13.38

(1.58)

11.85

(1.54)

8.17

(1.40)

9.63

(1.45)
Scenario

14

15

16

17

18

19

20

21

22

23

24

25
Mean

(s.d.)

9.41

(2.38)

9.56

(2.64)

7.86

(2.02)

7.08

(1.69)

7.94

(2.11)

8.95

(1.45)

12.43

(1.43)

11.49

(1.76)

12.25

(2.28)

10.81

(1.88)

10.61

(2.02)

13.45

(2.67) 
Table 2. Means and Standard Deviations of Data

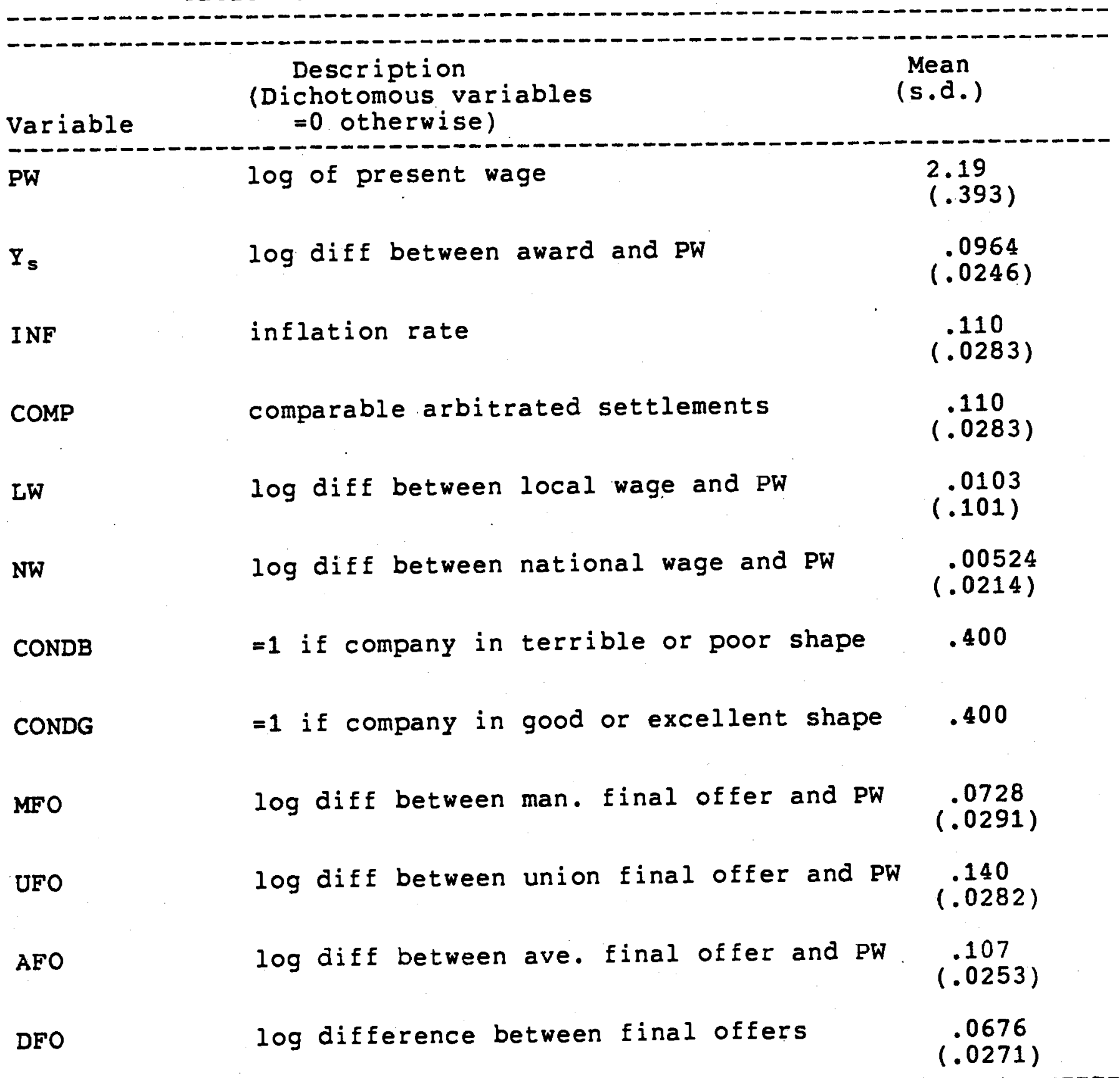

$N=1475$ (59 arbitrators $\times 25$ scenarios) 
Table 3:

Estimates of OLS Models of Arbitrator Decisions Dependent Variable $=Y_{s}$

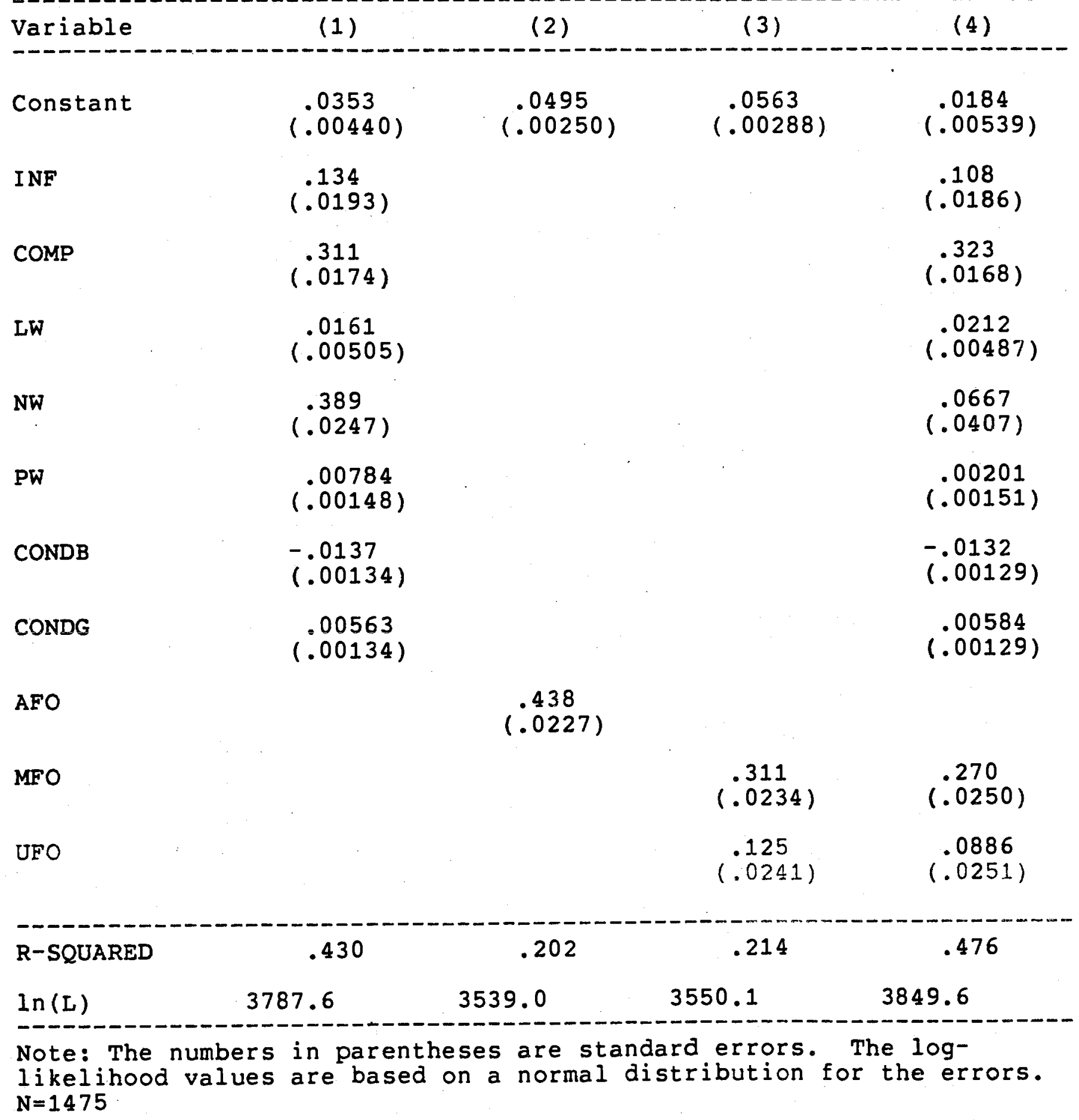


Table 4:

Estimates of Explicit Models of Arbitrator Decisions Dependent Variable $=Y_{S}$

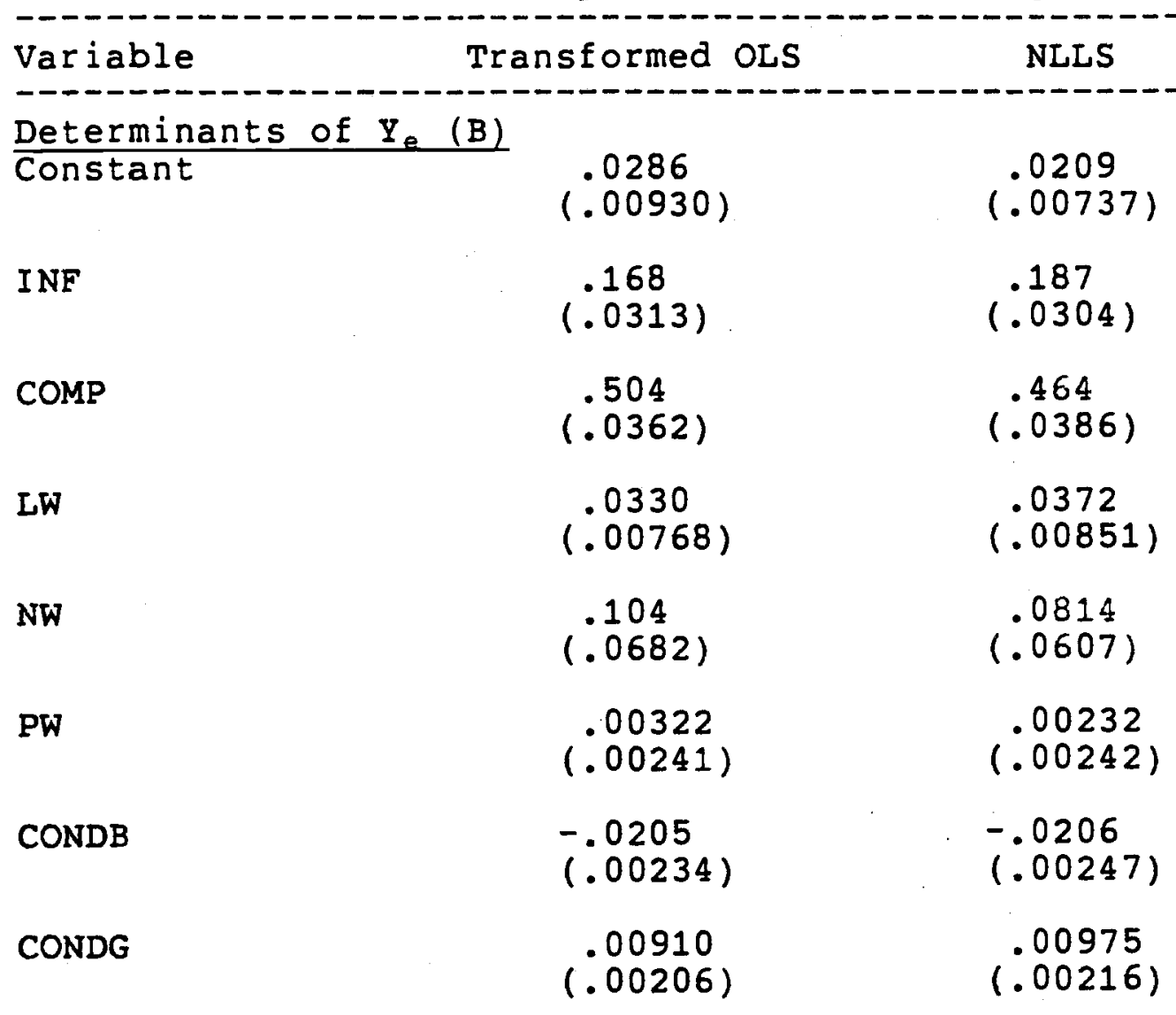

Weight on $Y_{e}(g)$

$\mathrm{g}$

.641

$(.0355)$

go

$-.0807$

$(.104)$

$9_{1}$

Relative weight on the management offer

\begin{tabular}{|c|c|}
\hline \multicolumn{2}{|r|}{$\begin{array}{l}.753 \\
(.055)\end{array}$} \\
\hline $\begin{array}{l}\text { SEE } \\
\ln (\mathrm{L})\end{array}$ & 3849.6 \\
\hline $\begin{array}{l}\text { Note: Th } \\
\text { transfor } \\
\text { fourth c } \\
\text { first or } \\
\text { the OLS } \\
9 \text {. The } \\
\text { the erro }\end{array}$ & $\begin{array}{l}\text { numbers in parentheses are asymptotic standard errors. The } \\
\text { med oLs estimates are based on the estimates contained in the } \\
\text { olumn of Table } 3 \text {, and its standard errors are derived from a } \\
\text { der approximation to the relevant nonlinear transformation of } \\
\text { parameters. The nonlinear model is defined in equations } 8 \text { and } \\
\text { log-likelihood values are based on a normal distribution for } \\
\text { rs. } N=1475 \text {. }\end{array}$ \\
\hline
\end{tabular}


Table 5:

Estimates of weight on arbitrator's notion of equitable award as a function of $\log$ difference in offers

$$
\begin{gathered}
(\mathrm{DIFF}=\mathrm{MFO}-\mathrm{UFO}) \\
(\mathrm{AVE}=\text { average value OF DIFF }=.0675)
\end{gathered}
$$$$
\text { ( } \mathbf{s d}=\text { standard deviation of } \mathrm{DIFF}=.0271 \text { ) }
$$

( $g$ = weight on arbitrtor's notion of equitable award)

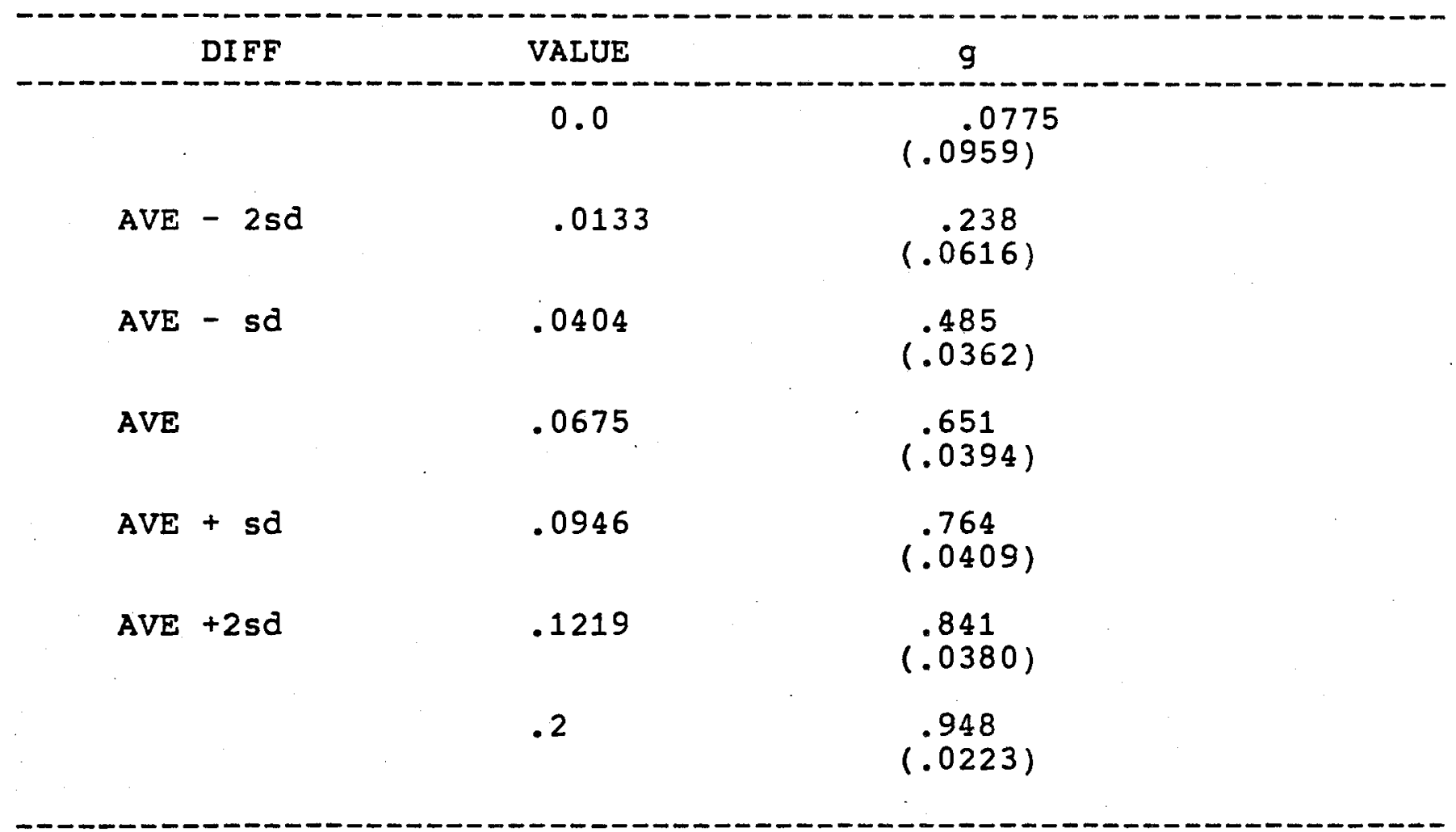

Note: The numbers in parentheses are aproximate asymptotic standard errors. They are derived from a first order approximation to the nonlinear transformation of the parameters contained in equation 9 . The estimates used are contained in the second column of Table 4. 